\title{
18 EPIDAT - Research Platform for Jewish Epigraphy
}

\begin{abstract}
EPIDAT, the research platform for Jewish epigraphy, deals with Jewish epigraphy in all its aspects. This article describes the on-going project and datadriven development, since the year 2002, which resulted in a wide range of access options to the epigraphic records. Later on, the solid data basis hosted by EPIDAT enabled cooperation across disciplines (linguistics, art history, monument science, cultural heritage agencies) and other epigraphic projects. Interoperability is essential for epigraphy, but needs reliable ontologies and cooperation over several projects and beyond disciplines.
\end{abstract}

Keywords: data analysis, interoperability, Jewish studies, semantic web, visualisation

\subsection{Introduction}

\begin{abstract}
"If there were a database containing as many inscriptions as possible from a huge number of cemeteries in Germany as well as Central and East Europe, we would then have a corpus of source material appropriate for many research questions; both known research questions as well as new ones - inter alia the study of the differences between eulogies for women and men" (Brocke \& Mirbach, 1988).
\end{abstract}

It would take almost 20 years before a database for Jewish epigraphy was established. In 2002 the Salomon Ludwig Steinheim-Institute for German-Jewish History (then located in Duisburg, now Essen) was commissioned to carry out the photographic and scientific documentation of the Ashkenazic Cemetery of the Jewish Communities of Hamburg and Altona. It was clear from the beginning that this task could only be effectively and adequately handled with the aid of computers. In order to present them in their entirety, more than 6,000 remaining objects required a digital edition. "It was [...] the sheer question of volume which led [...] to start considering electronic publication” (Roueché, 2010). A team of Hebrew and Jewish Studies specialists, together with art-historians and monument conservators defined the base structure, the principal set-up and the main categories needed in order to enable adequate research on the headstones preserved on this extraordinary cemetery. Even though the initial aim was to provide a straightforward method for accessing the rich

Thomas Kollatz, Salomon Ludwig Steinheim-Institute for German-Jewish History, Essen; Academy of Science and Literature, Mainz 
epigraphical collection, it soon become clear that a structured database would have been also a superior tool for all kind of current and future research. In 2006 EPIDAT was officially launched on the Internet. ${ }^{1}$

\subsection{EPIDAT Metadata Collections}

Based on several epigraphic projects in line with the Hamburg project, the database could constantly be developed and maintained (Kollatz, 2015).

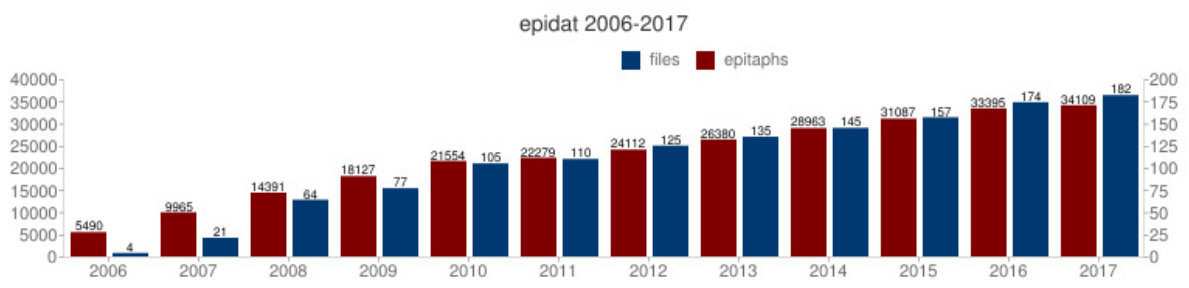

Figure 18.1: Epitaphs and files (per anno)

Currently it contains the digital collections of about 180 historic Jewish cemeteries, with the edition of more than 33,000 epitaphs and 65,000 image files (Figure 18.1). We are not dealing with "big data", but, in a sense, "long data” (Arbesman, 2013/01/29) or "small data” (Pollok, 2013/04/22) could be considered as a more proper term: the geographical focus is on Germany, but inscriptions from Jewish cemeteries in The Netherlands, and recently also from Lithuania and the Czech Republic are also collected. The time span ranges from the $11^{\text {th }}$ to the $20^{\text {th }}$ century, from the Medieval and Early Modern periods to the Modern Era.

The large spatial and chronological distribution of the resources requires a broad range of access points into the collections. Therefore, the epigraphical sources can be browsed through a number of filters that can be grouped as follows:

- Location-based filters: for users whose research interests focus on the epigraphical tradition of a single community or a certain region.

- Time-based filters for research into textual and visual features changing over time.

Epigraphs, both in their physical and in the textual aspects, are indexed. Indexes concern: symbols depicted on the headstones, word forms used in the inscriptions as well as quotations from the Hebrew Bible, references to rabbinic literature and

1 [http://www.steinheim-institut.de/cgi-bin/epidat]. 
liturgical books, persons mentioned on the inscriptions, and stonemasons involved in the craft, etc. Moreover, a full-text search helps finding keywords and idiomatic expressions.

A huge number of digital images can be browsed independently for chronology and by provenance.

Different kinds of maps show where any single cemetery is located as well as regions wherein a large number of cemeteries could be documented.

\subsection{Text Encoding}

In order to promote and to encourage reuse of EPIDAT-records, a machine-readable open interface has been made available. This web interface ensures that the epigraphical datasets are harvested and downloaded by third parties. Since 2008 EPIDAT records are provided in EpiDoc. ${ }^{2}$

A special opportunity was the cooperation between the EPIDAT team and building researchers, made possible by funding from the Federal Ministry of Education and Research (BMBF). The cooperation between "text-minded" and "object-minded" researchers proved to be useful and broadening. It appeared to be instructive to pay attention to the text-bearing objects themselves. It is not only the text, where "it" happens: cultural change is not only expressed by textual means, especially with respect to epitaphs, which by nature are a conservative and traditional medium. When text is fixed and subject to conventions, then the form of the objects could be the vehicle for change in religion, culture and society (Figure 18.2).

In the scope of the cooperative project, a preliminary object mark-up schema was developed that enabled us to merge textual and object-related data (Arera-Rütenik \& Kollatz, 2016). For this kind of transdisciplinary research perhaps, in the future, an "Object Encoding Initiative" could meet the requirements of less text-orientated disciplines such as art history, history of architecture, iconology and visual analytics. Digital epigraphy should take into account the methodological requirements of all involved disciplines. As far as the encoding of text is concerned, EpiDoc is a stable basis for all kinds of text-orientated approaches in philology, religious and cultural studies. The picture is different when it comes to encoding objects, which are more than just text-bearing objects:

"What characterises this class of objects is that they form a whole with their physical support. Indeed, the meaning of an epigraph cannot be fully understood without the analysis of the object or monument or other archaeological object on which it appears, just as one cannot fully understand the nature of that particular archaeological object without thoroughly investigating the sense of the inscription or iconographic representation it hosts" (Felicetti et al., 2016).

2 [http://www.stoa.org/epidoc/gl/latest/toc-it.html]. 

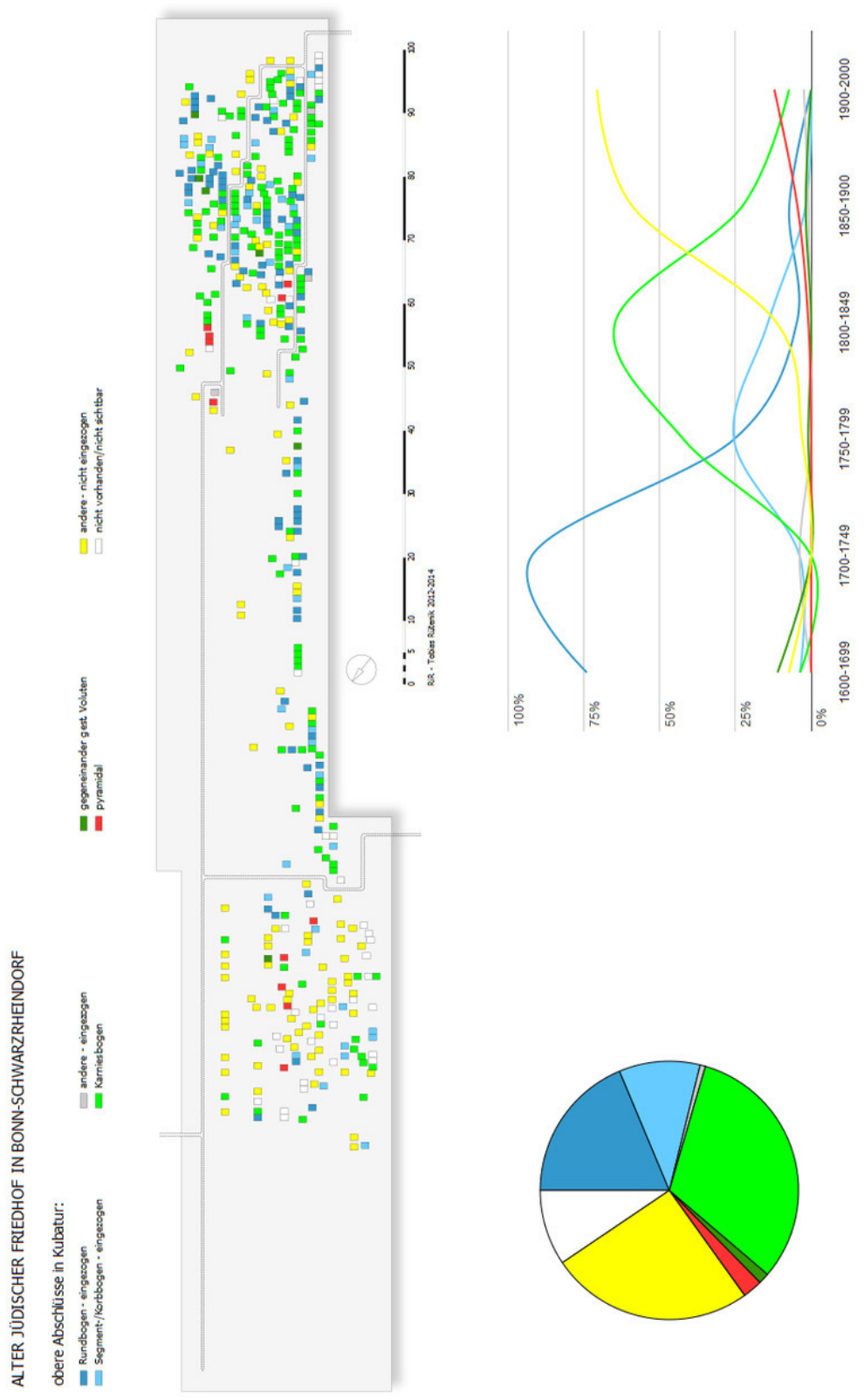

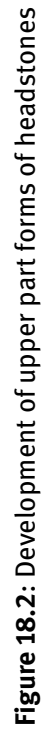


Epigraphy is an ancillary science and, indeed, it serves the vital purpose of the scientific community at large. Each and every object opened up and dealt with using epigraphic science is a unique source. Four specific features of the genre of the (Jewish) epitaph should not be underestimated:

- first, the fact that the majority of the objects can be precisely dated - by the date of death of the deceased person mentioned in the eulogy;

- secondly, the fact that the records can be located - by the place of burial;

- third, the fact that they could be clearly assigned to a gender - the headstone is erected to remember a certain man or woman, the eulogy reflects on her or his life, moreover it reflects common values a community of a certain period and a certain place have attributed to men and women;

- last, but not least, there is the sheer quantity of relevant data.

The stable quality of data and sufficient quantity of temporal, spatial and gender related information contributed by epigraphy, is suitable for a wide area of inter- and trans-disciplinary research questions. The names mentioned are a valuable source for genealogy and onomastic studies. The use of quotations from traditional literature in the eulogies testifies to the temporal preferences and spirit of a period. The same is true for the symbols shown on the headstones, and the materials and techniques used. The above-mentioned features can potentially contribute to both lexicography and linguistics.

Recently, EPIDAT provides in a beta-version the list of word forms sorted according to various criteria: words only occurring on inscriptions for women, occurrence of words related to time, and length, where longer words indicate Hebraised place and person names, etc. (Grüntgens \& Kollatz, 2018). A problem, which is currently still unsolved, is that we are still missing part-of-speech taggers and lemmatizers for the Medieval and Early Modern periods. A lemmatized list would probably allow more refined conclusions on the development of the Hebrew language in the Diaspora and the impact of external non-Jewish culture.

\subsection{Reuse of Data}

Via the interface, EPIDAT records were actually more than once harvested and reused, e.g. in the scope of so-called hackathons. During the "Coding Da Vinci" event, ${ }^{3}$ pushed forward by the Open Knowledge Foundation in order to make all kinds of cultural data available and known beyond the narrow framework of academic research, EPIDAT records were used by one of the project teams, and also during a pre-conference

3 [https://codingdavinci.de]. 
workshop to the Digital Humanities Conference 2014 in Lausanne. ${ }^{4}$ In addition, and perhaps just as important as these citizen science related activities, is the fact that the interface to EPIDAT allows and enables cooperation between disciplines.

EPIDAT metadata are also provided by a RSS-feed, not meant to describe every single headstone, but exclusively meant to provide information about the historical site and the history of the cemetery. These data are harvested on a regular basis by the mobile web application, "Places of Jewish History", a web service developed by Harald Lordick, a researcher at the Steinheim-Institute. The mobile web application displays historical information on places near the user's location, based on a wide range of relevant historical databases.

It is a remarkable fact that open and easy-to-use interfaces actually encourage all kinds of reuse. From a data curation perspective, it is equally important to enable traditional researchers to make good use of research data, as well as to ensure lowthreshold access to the TEI-XML encoded research data. The former are learned readers, who could contribute to the quality and the stringency of the content by commenting upon, and discussing it. The latter are skilled users, who could assess the general rationale of the data structure by transferring and reusing it. Both the critical response on content as well as on the data model, its structure and form, is becoming increasingly important to the emerging digital humanities.

\subsection{Interoperability}

EPIDAT makes use of the infrastructure of the German digital library TextGrid ${ }^{5}$ to enter and store data. TextGrid, in turn, adheres to the DARIAH network ${ }^{6}$ and provides its collections to the aggregator. Both of them enhance the visibility of the EPIDAT collections. For instance, more than 20,000 dated inscriptions as well as about 3,000 dated headstones displaying symbols can be visualized in their mutual, spatiotemporal relations through the DARIAH Geo-Browser. This allows us to point out the geographical and chronological distribution of epigraphs recording particular names, or utilizing specific symbols.

Data output is available in different formats and schema: HTML5 (for the online digital edition), EDM (for the exposure to the Europeana harvester), KML (for spatiotemporal visualization), RTF and PDF (for printed publications), CSV for indexes, word lists, and recently in RDF to express formally the relations between persons named on headstones.

\footnotetext{
4 [https://dh2014.org].

5 [https://textgridrep.org].

6 [https://de.dariah.eu].
} 
All research data provided by EPIDAT are released online under an open Creative Commons license (CC-BY). The editorial principles of Open Data and Open Access are strictly observed.

Interoperability is of vital importance to draw attention to the potential impact Jewish epigraphy and its findings could have on Jewish studies, as well as on the humanities at large. In order to foster interoperability, EPIDAT records are provided and constantly enriched with metadata referring to controlled vocabularies, authority files, ontologies and thesauri. What we are still missing are robust ontologies that meet our disciplinary requirements. There are useful authority files for places and names; ${ }^{7}$ however, the existing ontologies for $\mathrm{art}^{8}$ and iconography ${ }^{9}$ still lack appropriate categories for phenomena we come across in our specific domain.

We are aware that Jewish epigraphy is a marginal field of interest. A researcher interested in Hebrew poetry in the $17^{\text {th }}$ century is usually unaware that hundreds of sophisticated poetic eulogies are preserved in contemporary Jewish cemeteries. The same holds for the symbols and ornaments, which are widely neglected by art and images sciences. Likewise, nobody would expect that headstones could contribute to the history of everyday things like "fish traps", "ploughs", or "shoes”. A particularity of medieval cities was that houses were referred to by symbols. A certain man lived in the house marked by the symbol "shoe". From time to time this house name became a surname. It is remarkable that these house symbols are showing up on the headstones, also testifying to the development and change of everyday items over a long period (Figure 18.3).

The technical solution that could bring up all kinds of surprising findings of Jewish epigraphy to the surface is Semantic Web technologies. However, the way to the Linked Open Data cloud needs good preparation. Currently, we work together with neighbouring epigraphic projects, like Inscriptions of Israel and Palestine (IIP, Brown University) ${ }^{10}$ and the recently begun Funerary Inscriptions of Jews from Italy (FIJI, Utrecht University) within Jewish Studies. However, we also work with the long-term project Deutsche Inschriften (German Inscriptions) (DI, Academies of Sciences in Germany and Austria) (Schrade, 2011). All projects mentioned are EpiDoc based. In a bilateral working group between EPIDAT and DIO (German Inscriptions Online, Digital Academy at Academy of Sciences and Literature Mainz) ${ }^{11}$, we have used the generic XTriples webservice, designed to extract semantic relations existing in XML resources (in our case: EpiDoc TEI XML). The service was developed in the

7 For instance the CERL Thesaurus [https://www.cerl.org/resources/cerl_thesaurus/main] or the Library of Congress authority files [http://authorities.loc.gov].

8 Getty AAT [http://www.getty.edu/research/tools/vocabularies/aat/].

9 Iconclass [http://www.iconclass.nl/home].

10 [http://cds.library.brown.edu/projects/Inscriptions/index.shtml].

11 [http://www.inschriften.net]. 
context of the long-term research project, Deutsche Inschriften, together with the project Inscriptions in their Spatial Context by Torsten Schrade, head of the Digital Humanities department of the Academy of Science and Literature Mainz (Grüntgens \& Schrade, 2016). We succeeded in transforming TEI encoded family relations into RDFstatements as well mapping a complete corpus to CIDOC-CRM. The first results were promising and do lead us to rethink, evaluate and improve the shared data model, the TEI XML. Future plans are to provide structured data APIs, ideally a Sparql-Endpoint for both EPIDAT as well as German Inscriptions online.

In retrospect, in 2002 nobody expected EPIDAT to take such an evolution: what started as a practical workaround in order to handle one single historic cemetery, would develop into a research platform for Digital Jewish Epigraphy.

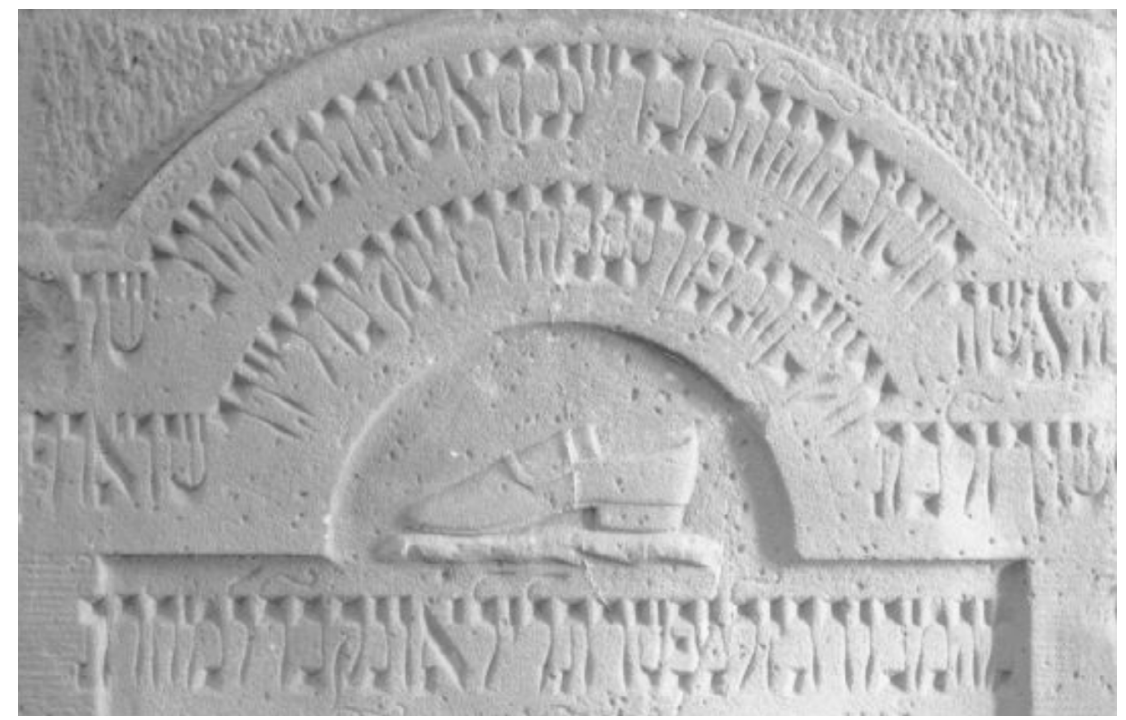

Figure 18.3: Buckled Shoe, Frankfurt 1795

\section{Bibliography}

Arbesman, S. (2013/01/29). Stop Hyping Big Data and Start Paying Attention to 'Long Data', Wired. Retrieved from [https://www.wired.com/2013/01/forget-big-data-think-long-data/], 2017/11/30.

Arera-Rütenik, T. \& Kollatz, T. (2016). Interdisziplinäre Perspektiven auf Grabmale und Visualisierung räumlicher Strukturen. Ergebnisse eines Projektes zu historischen jüdischen Friedhöfen. In A. von Kienlin, K. Keßler, U. Knufinke, \& S.M. Ross (Eds.), Objekt und Schrift: Beiträge zur materiellen Kultur des Jüdischen (Jüdisches Kulturerbe 1) (pp. 161-168). Braunschweig: TU Braunschweig.

Brocke, M. \& Mirbach, H. (1988). Grenzsteine des Lebens. Duisburg: Mercator. 
Felicetti, A., Murano, T., Ronzino, P., \& Niccolucci, F. (2016). CIDOC CRM and epigraphy: A hermeneutic challenge. In P. Ronzino (Ed.), Proceedings of the Workshop on Extending, Mapping and Focusing the CRM co-located with 19th International Conference on Theory and Practice of Digital Libraries (2015), Pozna, Poland, September 17, 2015. Retrieved from [http:// ceur-ws.org/Vol-1656/paper5.pdf], 2017/11/30.

Grüntgens, M. \& Kollatz, T. (2018). Korpusbasiertes Arbeiten und epigraphische Datenbanken: Möglichkeiten und Herausforderungen am Beispiel von Epidat und Dio. In J. Gessinger, A. Redder, \& U. Schmitz (Eds.), Korpuslinguistik (Osnabrücker Beiträgezur Sprachtheorie 92) (pp. 157-174). Duisburg: Universitätsverlag Rhein-Ruhr.

Grüntgens, M. \& Schrade, T. (2016). Data repositories in the Humanities and the Semantic Web: Modelling, Linking, Visualising. In A. Adamou, E. Daga, \& L. Isaksen (Eds.), Proceedings of the 1st Workshop on Humanities in the Semantic Web co-located with 13th ESCW Conference 2016 (pp. 53-63). Anissaras. Retrieved from [http://ceur-ws.org/Vol-1608/paper-07.pdf], 2017/11/30.

Kollatz, T. (2015). EPIDAT - Datenbank zur jüdischen Grabsteinepigraphik: Inventarisierung und Dokumentation historischer jüdischer Friedhöfe. In E. Bolenz, L. Franken, \& D. Hänel (Eds.), Wenn das Erbe in die Wolken kommt: Digitalisierung und kulturelles Erbe (pp. 161-168). Essen: Klartext.

Pollock, R. (2013/04/22). Forget Big Data, Small Data is the Real Revolution. Open Knowledge International Blog. Retrieved from [https://blog.okfn.org/2013/04/22/forget-big-data-smalldata-is-the-real-revolution/], 2017/11/30.

Roueché, Ch. (2010). Digitizing Inscribed Texts. In M. Deegan \& K. Sutherland (Eds.), Text Editing, Print and the Digital World (pp. 159-168). Farnham: Ashgate.

Schrade, T. (2011). Epigraphik im digitalen Umfeld, Skriptum, 1, 7-11. URN [urn:nbn:de:02892011051816]. Retrieved from [http://www.skriptum-geschichte.de/2011/heft-1/ epigraphik-im-digitalen-umfeld.html], 2017/11/30. 